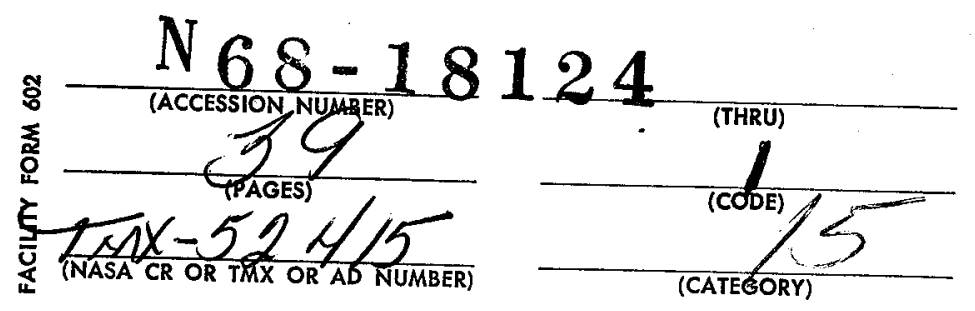

BEARINGS AND SEALS FOR CRYOGENIC FLUIDS

by $H$.W. Scibbe

Lewis Research Center

Cleveland, Ohio

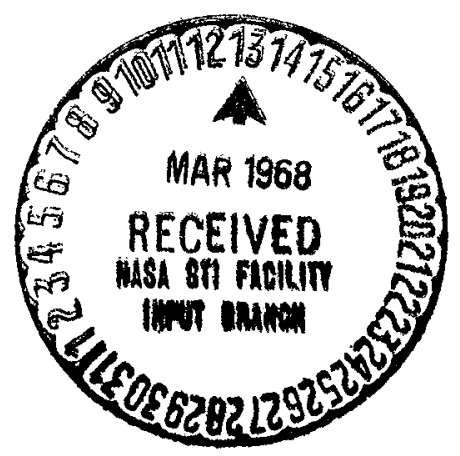

TECHNICAL PAPER presented at Fuels and Lubricants

Meeting sponsored by the Society of Automotive Engineers Cleveland, Ohio, November 13, 1967 


\title{
BEARINGS AND SEALS FOR CRYOGENIC FLUIDS
}

\author{
by H. W. Scibbe \\ Lewis Research Center \\ Cleveland, Ohio
}

TECHNICAL PAPER presented at

Fuels and Lubricants Meeting

sponsored by the Society of Automotive Engineers

Cleveland, Ohio, November 13, 1967

NA TIONAL AERONAUTICS AND SPACE ADMINISTRATION 


\title{
BEARINGS AND SEALS FOR CRYOGENIC FLUIDS
}

by H。W. Scibbe

\section{Lewis Research Center}

Cleveland, Ohio.

\begin{abstract}
Bearings and seals in rocket engine turbopumps operate directly in the cryogenic propellant. Special design and lubricating techniques are required since ordinary oils and greases become glasslike solids at these extremely cold temperatures. The bearing load carrying surfaces are lubricated by thin transfer films. The Iubricant is provided by the bearing cage which is usually fabricated from a self-lubricating Teflon compound. Material compatibility and wear are the important factors for face contact seals in these cryogenic fluids. Carbon, normally used in seal nosepieces, has violent reactions when run in liquid fluorine, an extremely chemically active fluid. Wear at the rubbing contact is minimized when the seal is designed for positive face separation with acceptable leakage.
\end{abstract}


INTRODUCTION

Present day aerospace applications require lubrication of surfaces in sliding and rolling contact under difficult and sometimes hostile environments. For example, in rocket engine turbopumps that pump high energy propellants, bearings and seals are exposed to extremely low temperatures and chemically active fluids. To optimize storage capacity, these high energy propellants are carried aboard the launch vehicle as cryogenic liquids or liquified gases. Some properties of these cryogenic liquids are shown in table $I(1) *$

The properties shown include freezing point, boiling point at atmospheric pressure, liquid density at the boiling point, and liquid viscosity. The liquids commonly used as propellants in rocket engines are liquid hydrogen ( $-423^{\circ} \mathrm{F}$, boiling point at atmospheric pressure) as a fuel, and liquid oxygen $\left(-297^{\circ} \mathrm{F}\right)$ and liquid fluorine $\left(-306^{\circ} \mathrm{F}\right)$ as oxidants. Liquid nitrogen $\left(-320^{\circ} \mathrm{F}\right)$ is commonly used as a refrigerant, more recently in the frozen food industry. Liquid methane $\left(-258^{\circ} \mathrm{F}\right)$, a commercial gas, is used in the liquid form to simplify storage and transportation.

Although adequate cooling capacity is provided by these cryogenic liquids, lubrication is required at surfaces in sliding and rolling contact. It is obvious from the low temperatures indicated for these liquids, that conventional lubricants cannot be used for bearings and seals in turbopump applications. For example, bearings operating at liquid hydrogen temperature

\footnotetext{
*Numbers in parentheses designate References at end of paper.
} 
$\left(-423^{\circ} \mathrm{F}\right)$ cannot be lubricated with normal liquid lubricants because this temperature is far below their pour point and oils and greases become brittle solids.

When reliable operation of the turbopump can be accomplished with the bearings operating in and cooled by the cryogenic liquid, bearing lubricating systems can be greatly simplified. The over-all complexity, weight, and cost of the turbopump system can thereby be appreciably reduced.

The load-carrying capacity of hydrodynamic bearings is proportional to the viscosity of the working fluid. This type of bearing therefore cannot be used in a cryogenic liquid because the viscosity is too low to generate any appreciable load capacity. As shown in table I, the viscosity of liquid hydrogen at its boiling point $\left(-423^{\circ} \mathrm{F}\right)$ is about one tenthousandth that of SAE 30 oil at $100^{\circ} \mathrm{F}$. The alternative is to use rolling element bearings that contain a solid lubricant to provide the lubricating function. Liquid hydrogen is a good coolant so it can be used effectively to remove the frictional heat generated in the bearing, but a lubricant is still required. Another reason for using rolling element bearings for cryogenic turbopumps is that they require only minuscule amounts of lubricant (2).

Although the bearings may be operated in the pumped fluid it is necessary, in some turbopump applications, to use a rotating seal to prevent leakage of the fluid around the shaft driving the pump. It is extremely important that these seals have essentially zero leakage, especially where the fluids are combustible. Face contact seals, which are the most common type of seal in use today, have also been used effectively in cryogenic 
turbopumps (2). Their design permits balancing of the hydraulic forces (pressure) acting on the seal nosepiece. A pressure-balanced design results in minimum leakage through the sealing gap and a long wear life.

The purpose of this paper is to present the material requirements and lubricating techniques presently used for rolling element bearings and face contact seals in cryogenic propellant turbopumps. Specifically discussed are the lubricating mechanism, cage design, and heat generation of ball bearings for liquid hydrogen turbopumps; and the design and material compatibility factors of face contact seals for liquid fluorine pumps.

BALI BEARING DESIGN FOR IIQUID HYDROGEN TURBOPUMPS

Ball bearings used in liquid hydrogen turbopumps have several basic material and design requirements. Among these are the selection of (1) a ball-race material; (2) a selfolubricating cage material, that provides lubricant on the bearing load carrying surfaces and has a long wearlife; (3) a cage design that has adequate strength and sufficient clearances at cryogenic temperatures; and (4) the internal design and geometric factors that minimize heat generation within the bearing due to ball spin.

Bearings in a hydrogen turbopump must operate at high rotative speeds under moderate thrust loads for short time periods. High speeds are essential because of the properties of the fluid. The bearing thrust loads are usually moderate because the large pressure force developed by the pump is equalized by a balance pressure device built into the turbopump. Because of the thrust load requirement, the design of a ball bearing will be specified.

Although the turbopump operates for only a few minutes (the duration of the rocket engine firing) a high degree of reliability is required by all 
turbopump components, including the bearings to preclude failure of an expensive and complex rocket engine system. Total bearing run time is usually 4 or 5 hours including system checkout and engine static firing tests.

\section{Ball -Race Materials}

In addition to the high compressive strength and hardness requirements necessary in bearing steels, properties such as corrosion resistance, dimensional stability, and lowatemperature ductility are required for ball and race materials used at cryogenic temperatures. Conventional SAE 52100 bearing steel and AISI 4400 stainless steel have both been used successfully as ball and race materials in cryogenic bearings applications (3,4, and 5). The 440C stainless steel exhibits properties similar to those of 52100 steel at these low temperatures, but is generally preferred because of its better corrosion resistance.

Early bearing experiments in liquid nitrogen and liquid hydrogen indicated that corrosion formed on SAE 52100 balls and races when thermal cycling back to room temperature occurred (3). During thermal cycling, condensation forms on the bearing surfaces, and, since they are cleaned free of protective oil or grease, they readily corrode.

Dimensional instability is produced in bearing steels, such as $440 \mathrm{C}$ stainless, as the result of appreciable amounts (10 to 15 percent by volume) of retained austenite in the crystalline structure after heat treatment. Conversion of the unstable austenite to martensite can result in an increase in physical bearing dimensions. The transformation to martensite is delayed and usually occurs during bearing service. This is particularly 
true when the bearings are operated at temperatures below that of the quenching bath, such as in cryogenic applications. Retained austenite in $440 \mathrm{C}$ stainless steel may be as large as 30 percent by volume depending on the austenitizing temperature, the quenching time, and the quenching bath temperature. To convert the retained austenite to martensite the steel is subcooled to $100^{\circ} \mathrm{F}$ or lower, immediately after quenching. Subcooling is followed by tempering to stabilize the newly formed martensite. When specifications require a minimum amount ( 3 percent or less) of retained austenite in the final structure, a second subcool and tempering cycle is performed. To insure maximum dimensional stability in $440 \mathrm{C}$ stainless and other bearing steels that will be used in cryogenic applications, subcooling followed by tempering is now generally specified as part of the heat cycle.

Although $440 \mathrm{C}$ stainless steel exhibits an increase in tensile (compressive) strength and hardness at cryogenic temperatures, it also experiences an increase in brittleness and a decrease in impact strength. Specific data on the low temperature ductility of $440 \mathrm{C}$ is not readily available, however it may be assumed that the balls and races do retain some ductility, even at temperatures as low as liquid hydrogen $\left(-423^{\circ} \mathrm{F}\right)$. Ring cracking has been observed in several cryogenic bearing applications, (5) probably as a result of excessive shrink fits between the $440 \mathrm{C}$ races and the shaft or housing materials. The results of preliminary experiments, with the bearings operating immersed in liquid nitrogen and hydrogen, indicated that the differential contraction rates of the various materials used can, upon cooling, affect bearing running clearance (4). The ball-race materials, 
the bearing mounting materials, and the mounting clearances therefore should be selected so as to minimize the reduction in bearing diametral clearance at the cryogenic temperature.

Since the required life of bearings operating in cryogenic turbopumps is only a few hours, rolling element fatigue is not considered a major cause of failure. It is generally recommended however, that the maximum Hertz compressive stress in the ball wrace contacts be limited to 350000 pounds per square inch. The primary cause of ball bearing failure in hydrogen turbom pumps has been excessive heat generation. The major sources of heat generation in the bearings are the ball spinning friction in the ball-race contact areas and the rubbing friction between the cage and balls, and the cage locating surface on one of the races. The heat generated within the bearing must be removed to assure an equilibrium operating condition and to prevent a total loss in operating clearance that results in seizure.

The measured, room-temperature, diametral and cage clearances in hydrogen turbopump bearings should be two to three times those required in high-speed oil lubricated bearings. The actual clearances specified are largely dependent upon the bearing size, the maximum operating speed, and the relative contraction rates between the ball-race and cage materials as the turbopump assembly is cooled to liquid hydrogen temperature $\left(-423^{\circ} \mathrm{F}\right)$ (4). Bearing Lubrication by Transfer Films

In a conventional lubrication system for ball bearings, surface integrity in the ball-race contact is maintained and surface welding prevented by the presence of contaminant surface films or by a lubricant that separates the surface asperities. 
Operation in liquid hydrogen is considerably more difficult because, as previously mentioned, conventional lubricants cannot be used and contaminant low shear films cannot be readily formed on the surfaces in a reducing atmosphere. To facilitate the formation of a transfer film on the balls and race grooves that prevents contact between the clean nascent metals, the bearings must be equipped with a cage constructed of a self-lubricating material. The surfaces that require lubrication in a ball bearing are shown in figure 1. The surfaces that require lubrication immediately when the shaft begins to rotate are those where pure sliding contact occurs, at the cage locating surface on the inner race and at the ball-cage contacts. These surfaces are easy to lubricate because they are in direct contact with the lubricant (cage material). The ball-race contacts where rolling with sliding takes place also require some lubricant, but lubrication here is more difficult. It has been speculated that lubrication at the ball-race contacts is obtained through transfer films also provided by the cage material. The film-transfer process is illustrated in figure 2. As the bearing rotates, the balls rub the self-lubricating cage. The cage material or lubricant transfers to the ball ans is subsequently transferred by the ball to the race grooves as thin films.

The best lubricant used to date for cryogenic applications has been Teflon (polytetrafluro ethylene). Teflon provides low friction at the bearsliding contacts, but it cannot be used in its pure form as a cage material because of poor strength properties and because of its tendency to cold flow even under the lightest loads. Teflon also has poor thermal conductivity which becomes a problem at high cage speeds, where heat generation in the 
bearing may become detrimental to successful operation. Teflon must therefore be compounded with other materials (fillers) to give it these desirable properties.

Experiments have been conducted with 40-millimeter-bore ball bearings operating in $-400^{\circ} \mathrm{F}$ gaseous hydrogen at $20000 \mathrm{rpm}$ and 200 pound thrust load. The bearings have operated satisfactorily for total running times up to 10 hours (6 and 7). Transverse profile traces were made on the inner $m$ race grooves to measure the film buildup from transferred cage material and determine the extent of race wear. Cage materials that exhibited good filmtransfer capability with long wear lives were (1) a laminated glass cloth with Teflon binder, (2) a glass-fiber-filled-Teflon, and (3) a bronze-filled Teflon. These three cage materials and the measurement of the transfer films are discussed in the following paragraphs.

Measurement of transfer films, - A profile tracing technique was used to study the formation and life histories of the transfer films on the bearing inner races. Several different cage materials were investigated. A crosssection of the bearing inner-race groove and a typical profile trace are shown in figure 3. As the stylus traces the race groove contour, a highly magnified profile trace is produced as shown in the lower portion of figure 3. of particular interest is the ball-track region where lubrication is required. The horizontal line shown on the profile trace is the original, race groove contour. The area of profile trace above the line is transfer film (lubricant) and the shaded area below the line is race wear. Successive profile traces were made at intervals of approximately 2 hours running time to study the history of the transfer films. 
Laminated-glass-cloth-with $*$ Teflon-binder cage material (38 percent glass cloth, 62-percent Teflon); " This material is currently used in several turbopump bearings. It is quite strong because of its laminated structure. Typical inner-race profile traces of a bearing using this cage material are shown in figure 4. IIlustrated is the life history of the transfer film for approximately ten hours total running time. After running for 284 minutes (fig. 4(c)) a fairly good film of lubricant has been deposited on the inner race. The scratches that appear in the film are indicative of abrasion caused by the glass in the cage material. With continued running, the film breaks down and wear of the inner race surface begins (fig。 4(d)). Race wear progresses with time and, after 10 hours running, the bearing is in danger of failing. The cause of the film breakdown and the large amount of race wear is probably abrasion by the glass fibers which are shredded from the cage material. This postulated abrasive-wear process is illustrated in figure 5. Shown are alternate layers of glass cloth and Teflon. The ball rotates and wears away the softer Teflon material. The Teflon is deposited in the race groove as the lubricant film. After a short time the Teflon has worn back leaving the glass cloth exposed to the rubbing action of the balls. Continued running results in film breakdown, caused by glass fibers which are shredded away from the cloth and embedded into the film. The film is worn away faster than it can be reformed by the Teflon and drastic race groove wear results, which eventually causes bearing failure.

Glass-fiber-filled Teflon cage material (15-percent glass fiber, 85percent Teflon). - In order to provide more Teflon and reduce the possibility of film destruction through abrasion, a second material was selected for 
evaluation. The progressive profile traces of the inner mace groove of a bearing using a 15-percent glass fiber, 85-percent Teflon cage is shown in figure 6. This material has good film forming capability and the film life appears to be somewhat longer than that of the glass cloth-Teflon laminated material. Its thermal conductivity is quite poor, however, so that adequate heat rejection becomes a problem at high bearing speeds.

Bronze-filled Teflon cage material (30-percent bronze powder, 70percent Teflon). - To improve the thermal conductivity of the cage material, Teflon has been compounded with metals such as bronze, copper, or silver. Bearings with bronze-Teflon cages have had excellent success in film transfer evaluation runs at $20000 \mathrm{rpm}$. This material has shown fairly good film formation with no apparent wear of the inner-race groove as illustrated in figure 7 .

The total cage wear, given as percent weight loss of the original weight, was 0.25 percent or less for the three materials discussed. This wear value is extremely low for a total bearing run time of approximately 10 hours (6). Bearing Cage Design

A second consideration for ball bearing cages used in liquid hydrogen turbopumps is their design. In addition to the self-lubricating feature, other properties of the cage material such as mechanical strength, structural rigidity, and wear resistance must be acceptable.

Mechanical strength at cryogenic temperatures must be accompanied with a good strength-to-weight ratio. Materials that do not have sufficient strength by themselves should be reinforced on their outer surfaces with metal shrouds. Structural rigidity is required because the cage material must be rigid 
enough to withstand deformation, but not become so brittle at cryogenic temperatures that it fails by cracking.

In addition to the strength and rigidity requirements, the material must have good wear resistance. In order that material wear resistance be used to its full advantage, the cage must be designed with proper ball-pocket and cage-locating (land) clearances.

Inner-race located cage design. - Three designs used successfully for inner race located cages are shown in figure 8. These designs were used in 40 millimeter ball bearings run in $400^{\circ} \mathrm{F}$ hydrogen gas at $20000 \mathrm{rpm}$ and. 200 pound thrust load. Of the three designs illustrated in figure 8 the one selected for a particular turbopump bearing is usually dependent upon the strength and the strength-toweight ratio of the cage body materials at the cryogenic temperature.

Outer-race located cage design. - Other cage designs that have been used successfully in the NERVA (8) (Nuclear Engine for Rocket Vehicle Application) and other (5) turbopump bearings are shown in figure 9. The conventionally designed cage (fig. $9(a)$ ) has a heavy cross-section with reinforcing side plates, similar to the inner race located design shown in figure 8(b). Because of the large rotating mass the cage generates considerable heat at the outer-race locating surface.

The thin-line, lighter weight design shown in figure $9(b)$ is flexible and sufficiently strong because it depends on the rigidity of the outer race for reinforcement. The open design also permits greater thru-flow of liquid hydrogen and therefore results in better cooling efficiency of the bearing than does the conventional cage design. The laminated-glass-cloth-with-Teflon- 
binder cage material has been used successfully with the thin line design in several turbopump bearings ( 5 and 8 ).

Cage clearances. As indicated previously (p.7), the cage clearances specified for hydrogen turbopump bearings are somewhat dependent upon the relative contraction rates between the ball-race and cage materials, as the bearing is cooled to $-423^{\circ} \mathrm{F}$. The total linear contraction from 70 to $-423^{\circ} \mathrm{F}$ for $440 \mathrm{C}$ stainless steel, ball and race material, is approximately 0.0019 inch per inch (9). In contrast the contraction for 100 percent TFE (polytetrafluoroethylene) Teflon is 0.0215 inch per inch (10) more than an order of magnitude greater over the same temperature range. Filler materials added to Teflon resin will reduce the total contraction depending upon the shape of the fillers, whether they are fibrous or spherical, the amount added in weight percent, and their coefficients of contraction. Fibrous fillers (glass fibers) produce the greatest reduction in contraction in the direction perpendicular to the molding pressure; spherical fillers (bronze powder) tend to equalize contraction in both directions (11). The laminated-glasscloth-with-Teflon-binder material has the greatest contraction in the direction of the glass cloth layers. Filled Teflon cages are usually made from molded tube stock with the molding pressure direction parallel to the axis of the tube (cage). The laminated Teflon cages are also made from tube stock. The tube is made by continuously wrapping glass cloth on a mandrel and binding the successive layers together with Teflon resin.

The total contraction from 70 to $-423^{\circ} \mathrm{F}$ of several filled Teflon and the laminated-glass-cloth Teflon materials are given in table II. The materials shown are similar to cage materials discussed previously。 It can 
be noted that the glass-fiber-filled and the laminated-glass-cloth Teflon materials exhibit anisotropic contraction with respect to the cage radial and width directions. The radial direction is perpendicular to direction of molding pressure for the glass-fiber - filled material and through the glass cloth layers for the laminated-glass-cloth material, as noted in table II. The bronze filled Teflon has the same contraction in both directions. Contraction in the radial direction will decrease the cage locating clearances, for inner-race located cages, whereas contraction in the width direction will decrease ball-pocket clearances. With filler materials or glass cloth layers, the total contraction of the Teflon cage materials shown in table II, .. range from four to eight times greater than that for the $440 \mathrm{C}$ ball and race material.

Typical locating race and ball pocket clearances for seven cage materials are shown in table III. The first four cages listed are fabricated from Teflon based materials and have contraction properties similar to those described above. Their innerwrace locating clearances range from 0.017 to 0.038 inch and the ball-pocket clearances from 0.014 to 0.026 inch.

The relative contraction of cage reinforcing materials such as aluminum and stainless steel can also affect cage clearances at cryogenic.temperatures. The total contraction for 2024 aluminum is about 0.0042 in per inch, whereas that for AISI 410 or 416 stainless steel is approximately 0.0019 inch per inch, from $70^{\prime}$ to $-423^{\circ} \mathrm{F}(10)$, which is the same as the $440 \mathrm{C}$ ball and race material.

In table III bearings, cages using materials 1, 3, and 7 were reinforced with aluminum. Cages fabricated from materials 5 and 6 used stainless steel 
shrouds. A glass fiber-filled Teflon cage (material 3, table III) supported with a riveted aluminum shroud experienced ball pocket cracking after running about 8 hours in $-400^{\circ} \mathrm{F}$ hydrogen gas. The cracking was partly caused by the different contraction rates between the glass fiber filled Teflon body (0.0164 in./in.) and the aluminum shroud (0.0042 in./in.). A more complete analysis of the cage failure is discussed in the following section.

Cage failure mechanisms. - An example of a brittle failure of a cage material (material 7, table III) is illustrated in figure 10(a). The molyb denum disulphide-(MoS 2$)$ filled-polyimide cage experienced complete failure after running only 22 minutes in hydrogen gas at $-400^{\circ} \mathrm{F}$. The cage design was similar to that shown in figure $8(\mathrm{c})$.

When an inner-race located cage is cooled to cryogenic temperature, insufficient clearance at the locating race will cause binding and the excessive heat generated at the surface may lead to cage failure. Bearing 23-S in table III is an example of a cage with insufficient clearance. In the initial run the bearing was brought to a complete stop from 5000 rpm with a 200 pound applied load.

The combination of a larger-than-required inner-race clearance and poor wear resistance can also result in cage failure. A silver composite cage (bearing 11-5, table III) fitted with a stainless steel shroud experienced this type of failure. The bearing had run in $-400^{\circ} \mathrm{F}$ hydrogen gas at $20000 \mathrm{rpm}$ and 200 pounds for 138 minutes. The bearing after test is shown in figure 10(b). During bearing operation the shroud had rubbed on the outer-race band and moved relative to the cage body. The balls wore into the shroud and jammed the bearing. 
Although a cage material may have good wear resistance, failure can result from structural deficiency in the material even when reinforcing is used. The delamination of the laminated-glass-cloth-with-Teflon-binder cage material is shown in figure $10(\mathrm{c})$. After running 349 minutes, this cage delaminated between two ball pockets. Delamination probably resulted from insufficient Teflon binder between the cloth layers, or from an improper curing technique during lamination.

The glass-fiber-filled Teflon cage material reinforced with a riveted aluminum shroud also showed structural weakness. After running 464 minutes, cracks appeared in a ball pocket of the cage (fig. 10(d)). It is speculated that the cracks resulted from the difference in contraction rates between the Teflon cage body and the aluminum shroud. The body shrank away from the shroud when the bearing was cooled to $-400^{\circ} \mathrm{F}$. When the bearing was subsequently run at high speed, centrifugal growth of the body between rivets caused fracture of the cage at the thin web section. Subsequent runs were made in $-400^{\circ} \mathrm{F}$ hydrogen gas with other bearings using glass-fiber-filled Teflon cages without aluminum shrouds. No pocket cracking occurred in these cages when the bearings were run at speeds to $40000 \mathrm{rpm}$.

Heat Generated Within a Ball Bearing

The problem of operating at high speed in a marginal lubricating fluid is that of maintaining a heat balance within the bearing. A heat balance can be accomplished by designing the bearing for minimum heat generation and then removing the heat generated with the hydrogen coolant (liquid or gas). One of the major sources of heat generation in a ball bearing operating under thrust load is the spinning which occurs in the contact between the balls 
and one race. Spinning occurs between the balls and one race in all ball bearings that operate under a thrust or combined thrust and radial load. Heat generation due to change in contact angle. - As shown in figure 11, a bearing under thrust load operates at same contact angle, $\beta$. At low speeds, the contact angles $\beta$ are equal at the inner and outer race contacts (fig. 11(a)). When the bearing is operated at high speed, ball centrifugal force creates an additional load at the outer race contact which results in unequal contact angles at the inner and outer race contacts (fig. 11(b)). The magnitude of this difference in operating contact angles further increases ball spinning and consequently more heat is generated by the bearing. Effect of bearing design and geometric factors on heat generation. - An analysis was made and programmed on a digital computer to determine the design and geometric factors that influence heat generation rates in a high speed ball bearing operating in liquid hydrogen. The computer results, which were supported experimentally with data from the bearing test program, indicate that the following factors contribute to lower heat generation rates: (1) open race curvatures (i.e., larger value for ratio of race groove radius to ball diameter than for bearingsdesigned for oil lubrication), (2) small ball diameter, (3) ball spinning at the race with larger curvature. The results of the computer program for ball bearings of 40 millimeter bore size with two different ball diameters and using two race curvature combinations are shown in table IV. The heat generated due to ball spin is converted to shaft torque. The torque values are for ball spin at the inner race contact, and are for a 100 pound thrust Ioad (T) at a shaft speed (N) of $40000 \mathrm{rpm}$ with an initial contact angle $(\beta)$ of 10 degrees. The ballspin friction coefficient (f) of 0.56 is for $440 \mathrm{C}$ stainless steel sliding 
on itself at liquid hydrogen temperature $\left(-423^{\circ} \mathrm{F}\right)$. The 108 series bear ings have a 0.375 -inch-ball diameter and the 1908 series have a 0.250 -inchball diameter. The 108 series bearings have larger values of torque for both race curvature combinations due to the greater heat generated by the larger ball size. Increasing the race curvature at the spinning contact from 0.51 to 0.52 causes the torque values to decrease for both the 108 and 1908 bearings. Note that the large decrease in torque from the 108 bearing with an inner-race curvature of 0.51 to the 1908 bearing with an inner-race curvature of 0.52 is a function of both ball size and race curvature.

The turbopump for the Nerva engine has a design speed of $24000 \mathrm{rpm}$. The pump ball bearings are 50 millimeter angular contact type (210 series) and operate at a rated thrust load of 2000 pounds (8). A computer analysis similar to that described for the 40 millimeter bearing above, was made for the 210 series bearings to indicate the effect of several race curvature combinations on ball spin torque. The torque values are plotted in figure 12 for shaft speeds from 15000 to $30000 \mathrm{rpm}$. They are plotted for ball spin at the outer-race contact using three race curvature combinations at a thrust load of 2000 pounds, and an initial contact angle of 20 degrees. Increasing the outer-race curvature from 0.52 to 0.54 decreased the torque approximately 40 percent throughout the speed range. Increasing the outerrace curvature to 0.58 decreased the torque approximately 70 percent from the 0.52 curve. An effect of ball centrifugal force on the outer-race contact can be seen in the lowest curve. The ball spinning changes from outer race to inner race at approximately $27000 \mathrm{rpm}$. This transition occurs because at the higher rotative speeds, ball centrifugal force increases and the balls 
grip the 0.58 outer-race contact more firmly. Ball spinning, therefore, occurs at the 0.54 inner-race contact and considerably more heat is generated. This transition from spinning at the outer-race contact to spinning at the inner-race contact would not occur as long as the shaft speed of $24000 \mathrm{rpm}$ is not appreciably exceeded. In the Nerva turbopump bearing test program, several bearings with 0.52 outer -0.52 inner-race curvatures and the 0.54 outer -0.58 inner-race curvatures have been run in liquid hydrogen at 24000 rpm at thrust loads to 2000 pounds, for operating times up to 90 minutes. These bearings were run with force-fed liquid hydrogen thru flow.

Thrust bearing configuration for high DN values. - For the first three shaft sizes show in table $V$, the bearings operate at DN values (bearing bore in mm times shaft speed in rpm) to 2 million. As the ball diameter increases, the ball centrifugal force at the outer-race contact increases for these three bearings. As indicated previously in table IV, larger ball diameters adversely affect heat generation rates in a bearing operating at high speed. A conventional series 250 millimeter bore bearing is fitted with 2.375-inch dimeter balls. As shown in table $\mathrm{V}$, the centrifugal force per ball at a DN value of 4 million is 17300 pounds. This load value exceeds the capacity of the ball-race contact.

One solution to problems of ball centrifugal force at high DN values, is to use smaller diameter balls. This concept is illustrated by comparing the centrifugal force of 0.625 and 0.875 -inch diameter balls for the 150 and 200 millimeter bore bearings, respectively with that for the 250 millimeter bore size. For a bearing with a DN value of approximately 4 million, reducing the ball diameter from 2.375 to 0.625 inch decreases ball centrifugal force by a factor of 30 . 
The load capacity of a ball bearing operating under thrust load is proportional to the product of the number of balls $(n)$ and the square of the ball diameter $\left(a^{2}\right)$. In order that the load capacity not be appreciably reduced when decreasing the ball diameter, it is necessary therefore to increase the number of balls in the bearing. There is a practical limit for reducing ball diameter or increasing the number of balls and that is the cage strength, especially between adjacent ball pockets. If the cage annular cross-section is reduced excessively it may break at high speed because of inadequate strength.

FACE CONTACT SEAL DESIGN FOR LIQUID FLUORINE TURBOPUMPS

\section{Face Contact Seals}

In some turbopump applications rotating shaft seals are required. These turbopump designs contain various cryogenic fluids at pressures different from the surrounding space. Intolerable leakage of the fluid along the shaft is avoided by means of dynamic seals (2).

Face contact seals, which are the most common type of seal in use today, exist in a variety of forms, but most have the essential arrangement shown in figure 13. The sketch in the upper right-hand corner shows the location of a seal on a pump shaft sealing pump outlet pressure $P_{1}$. The seal consists of two main parts, (I) a seal seat which is fixed to the shaft and rotates with it, and (2) a nosepiece flexibly attached to the stationary shaft housing. A piston ring secondary seal permits axial movement of the nosepiece. A sealing dam is formed by the nonrotating nosepiece which is held by a force from the spring and the sealed fluid pressure in rubbing contact or close proximity to the rotating seal seat. The sealing gap is 
shown exaggerated, and leakage is outward to the surrounding low pressure $P_{0}$.

The sealing gap is at the wearing surfaces between the seal seat and nosepiece. The success of the seal is determined largely by what occurs at this gap. For most applications, the gap is very small, around 10 to 500 millionths of an inch; for comparison, journal or hydrodynamic bearings usually have film thicknesses of 500 millionths of an inch and greater. Leakage rate through the gap is very largely dependent on sealing gap opening (fig. 13). If the sealing gap increases by a factor of 10, say from 10 to 100 millionths of an inch, the leakage increases by a factor of 1000. Even with positive face separation, however, the leakage can be very low providing the gap is small enough. The fact that the sealing gap is very small means that small variations and distortions in the sealing faces become significant.

Seal wear occurs when the nosepiece rubs on the seal seat. For long seal life, the seal must have positive face separation, which is maintained. by the pressure of the fluid that leaks across the face. Contact between the nosepiece and seat occurs only during start and stop, or during brief periods of severe overloads. Positive face separation with acceptable leakage is inherently tied to balance of hydraulic forces acting on the seal nosepiece.

Pressure balancing of face contact seals. - An unbalanced face contact seal which shows the hydraulic forces acting on a cylindrical nosepiece is illustrated in figure 14. The sealed pressure force on the nosepiece is represented by the rectangular area; the gap pressure force is represented by the triangular area, since the pressure decreases linearly across the gap 
from inside to outside. If the secondary seal piston ring is placed on the nosepiece outer diameter (fig. 14(a)), the sealed pressure force behind the nosepiece exceeds the gap pressure force and the nosepiece is forced against the seal seat. This is a pressure loaded seal and has high face loads that can produce high wear rates. If the piston ring is located at the inner diameter (fig. 14(b)) the sealed pressure no longer acts behind the nosepiece. Therefore, the gap pressure opens the seal. This seal is pressure unloaded and, of course, leakage is very high. However, a diameter can be selected for the piston ring (as shown in fig. 15) such that sealed pressure force behind the nosepiece exactly balances the gap pressure force. This is a 100 percent pressure balanced seal, and only light spring loads hold the nosepiece in position.

Compensating pressure design. - Positive gap control is obtained in this design by having the sealing gap perform as a hydrostatic thrust bearing. As shown in figure 16, the seal design is similar to that shown in figure 15, except that a recess and a series of orifices, arranged circumferentially around the seal, have been added to the nosepiece face. The recess pressure, $P^{\prime}$, is a function of gap size and the orifices and recess areas can be designed to maintain a satisfactory gap opening. Acceptable leakage rates with minimal nosepiece wear are thereby obtained at the turbopump design point. Off-design operation of pressure-balanced and pressure-compensated seals. - The pressure-balanced and pressure-compensated seals, described in the preceding section, were designed for positive face separation at the sealing gap at the turbopump design point. Operation of the pressurebalanced seal over a range of speeds would still provide positive face 
separation between the nosepiece and seal seat, provided the spring seating load was small. In the pressure-compensated design however, the recess pressure, $P^{\prime}$, (fig. 16) may not be sufficient to provide liftoff (positive face separation) at low pump pressures (low speed operation), since the recess areas and orifice sizes are selected at the turbopump design point. Without seal liftoff it would be expected that higher wear of the nosepiece would occur.

\section{Seal Design for Liquid Fluorine}

Material selection. - Special problems arise when the fluid to be sealed is very corrosive. For example, a shaft seal for a liquid fluorine centrifugal pump was required. Fluorine is one of the most corrosive of known chemicals. Early seals for fluorine pumps used carbon nosepieces, which had been used successfully in liquid oxygen. Attempts to run these seals resulted in pump failure and severe fires which were traced to fluorine reaction with the carbon nosepiece of the seal.

Since fluorine was, obviously, too active chemically for the safe use of carbon materials in seals, other materials, such as metal fluorides which are compatible with fluorine, were selected. Whenever metals are exposed to liquid fluorine, a passivated surface layer of metal fluoride is formed. One of the better metals for liquid fluorine service is nickel. Friction and wear experiments showed that nickel fluoride appeared to have promise for providing a protective layer with low friction. Accordingly, a nickel-bonded titanium carbide cermet that forms nickel fluoride films was studied in liquid fluorine. Data from experiments in liquid oxygen and fluorine shown in figure 17, give a comparison of two potentially useful material 
combinations. The graphitic carbon material, which was not run in fluorine, is one of the best materials for use in liquid oxygen and is given as a standard for comparison. The aluminum oxide on nickel-bonded carbide had. better performance than aluminum oxide on itself. Further, the nickelbonded carbide in fluorine had friction and wear properties comparable with the carbon in oxygen.

Iiquid fluorine seal. - These friction and wear studies led to the selection of an aluminum oxide nosepiece, and nickel-bonded titanium carbide for the seal seat. Evaluation of this combination in liquid fluorine in a subsequent seal study using a pressure balanced design (fig. 18(a)) confirmed the lubricating mechanism suggested from the friction experiments. This lubricating mechanism is illustrated in figure 18(b) which shows the seal schematically. The fluorine reacts with the nickel binder to form a low shear strength nickel fluoride film. This film is an impervious coating that limits the extent of fluorine reaction and provides both low friction and wear. If the film is ruptured, it is quickly repaired by fluorine reaction with the nickel. To date, more than 20 pump tests have been made using the aluminum oxide and nickel-bonded titanium carbide seal materials. An additional 13 rocket engine firings have been completed using these seals in the fluorine turbopump. Performance has been very good, and the total time accumulated in the tests is more than Il hours. For rocket engine applications, this an appreciable amount of experience. The average running time during the pump tests far exceeded the normal firing time of the rocket engine. 
SUMMARY

Bearings and seals used in rocket engine turbopumps pumping cryogenic liquids have specific lubrication, material, and design requirements.

Rolling element bearings for liquid hydrogen turbopumps are lubricated by thin transfer films provided by a self-lubricating cage material, which is usually a Teflon compound. The following factors are emphasized for a good bearing design:

1. The formation and life histories of transfer films on the bearing load-carrying surfaces must be sufficient to provide bearing lubrication for several hours without any race wear. The lubricating capability and wear of several filled-Teflon cage materials have been evaluated for bearing running times up to 10 hours.

2. In addition to the self-Iubricating feature, the cage must have adequate strength and be designed with proper clearances to prevent seizure or excessive wear that can result in premature bearing failure.

3. Minimum heat generation at high operating speed can be obtained by designing the bearing with open race curvatures and small ball diameters.

Face contact seals for liquid fluorine turbopumps should be designed for positive face separation with acceptable leakage at the sealing surface. Positive face separation can be achieved by balancing the hydrostatic forces between the nosepiece and the seal seat (pressure balanced design).

In the absence of positive face separation at the sealing gap, some type of solid lubrication is necessary. Materials selected for the nosepiece and seal seat must be compatible with liquid fluorine. Nickel fluoride solidlubricant film was formed by the reaction of liquid fluorine with a nickelbonded titanium carbide seal seat. This seat material in combination with an aluminum oxide nosepiece showed good performance with satisfactory seal Iife in an actual liquid fluorine turbopump application. 
REFERENCES

1. E. E. Bisson and W. J. Anderson, "Advanced Bearing Technology," INASA SP-38, 1964, pp. 289-291.

2. E. E. Bisson, W. J. Anderson, R. L. Johnson, E. V. Zaretsky, and L. P. Ludwig, "Lubricants, Bearings, and Seals." Conference on Selected Technology for the Petroleum Industry, NASA SP-5053, 1965, pp. $103-123$.

3. K. B. Martin and R. B. Jacobs, "Testing and Operation of BaII Bearings Submerged in Liquified Gases," ASTE Trans., Vol. 2, No. 1, 1959, pp. 101-107.

4. H. W. Scibbe and W. J. Anderson, "Evaluation of Ball-Bearing Performance in Liquid Hydrogen at DN Values to 1.6 Million," ASLE. Trans., Vol. 5, No. 1, 1962, pp. 220-232.

5. H. Hanau, "Cryogenic Bearings," Machine Design, Vol. 36, June 4, 1964, pp. $122-128$.

6. D. E. Brewe, H. W. Scibbe, and W. J. Anderson, "Film-Transfer Studies of Seven Ball-Bearing Retainer Materials in $60^{\circ} \mathrm{R}\left(33^{\circ} \mathrm{K}\right)$ Hydrogen Gas at 0.8 Million DN Value," NASA TN D-3730, 1966.

7. E. V. Zaretsky, H. W. Scibbe, and D. E. Brewe, "Studies of Low and High Temperature Cage Materials," Bearing and Seal Design in Nuclear Power Machinery, R. A. Burton, ed., ASME, 1967, pp. 33-51.

8. J. B. Accinelli and F. X. Andrews, "Effect of Nuclear Radiation on the Performance of Liquid Hydrogen Cooled Rolling Element Bearings," Bearing and Seal Design in Nuclear Power Machinery, R. A. Burton, ed., ASME, 1967, pp. 492-503. 
9. F. R. Schwartzberg, et al., "Cryogenic Materials Data Handbook," Martin Company (AFML-TDR-64-280, DDC No. AD-609562), August 1964.

10. R. E. Mowers, "Program of Testing Nonmetallic Materials at Cryogenic Temperatures," Rocketdyne Div., North American Aviation, Report R-3498, December 30, 1962.

11. J. T. O'Rourke, "Design Properties of Filled-THE Plastics," Machine Design, Vol. 34, September 13, 1962, pp. 172-180.

12. W. F. Hady, G. P. Allen, H. E. Sliney, R. L. Johnson, "Friction, Wear, and Dynamic Seal Studies in Liquid Fluorine and Liquid Oxygen," NASA TN D-2453, 1964. 
TABLE I - PROPERTIES OF CRYOGENIC LIQUIDS (ref. 1)

\begin{tabular}{|l|c|c|c|c|}
\hline Liquid & $\begin{array}{c}\text { Freezing } \\
\text { Point, } \\
\text { F }\end{array}$ & $\begin{array}{c}\text { Boiling } \\
\text { Point, } \\
\text { F }\end{array}$ & $\begin{array}{c}\text { Liquid Density at } \\
\text { Boiling Point, } \\
\text { lb/cu ft }\end{array}$ & $\begin{array}{c}\text { Liquid Viscosity } \\
\text { at Boiling Point, } \\
\text { reyns }\end{array}$ \\
\hline Helium & $\mathrm{b}-458$ & -452 & 7.6 & $7 \times 10^{-10}$ \\
Hydrogen & -434 & -423 & 4.4 & 19 \\
Nitrogen & -346 & -320 & 50.1 & 230 \\
Fluorine & -360 & -306 & 94.0 & 372 \\
Argon & -309 & -303 & 87.4 & -2 \\
Oxygen & -361 & -297 & 71.2 & 274 \\
\hline Methane & -299 & -258 & 25.8 & - \\
\hline
\end{tabular}

Q Viscosity of $\operatorname{SAE} 30$ oil at $100^{\circ} \mathrm{F}$ is approximately $10^{-5}$ Reyn.

${ }^{b}$ At pressure of $26 \mathrm{~atm}$.

TABLE II - TOTAL CONTRACTION OF TFE TEFLON MATERIALS FROM 70 to $-423^{\circ}$ F (frcm Ref. 10)

\begin{tabular}{|c|c|c|}
\hline $\begin{array}{c}\text { Material } \\
\text { (weight percent) }\end{array}$ & $\begin{array}{l}\text { Total Contraction } \\
\text { in cage radial } \\
\text { direction (1) } \\
\text { (in./in.) }\end{array}$ & $\begin{array}{l}\text { Total Contraction } \\
\text { in cage width } \\
\text { direction (?) } \\
\quad \text { (in./in.) }\end{array}$ \\
\hline 100\% Teflon & 0.0215 & $\begin{array}{l}\text { Same as r dial } \\
\text { direction }\end{array}$ \\
\hline $\begin{array}{l}15 \% \text { Glass fibers } \\
85 \% \text { Teflon }\end{array}$ & $0.0084^{(3)}$ & $0.0164^{(3)}$ \\
\hline $\begin{array}{l}25 \% \text { Glass fibers } \\
75 \% \text { Teflon }\end{array}$ & 0.0090 & 0.0165 \\
\hline $\begin{array}{l}65 \% \text { Bronze } \\
35 \% \text { Teflon }\end{array}$ & 0.0140 & $\begin{array}{l}\text { Same as radial } \\
\text { direction }\end{array}$ \\
\hline $\begin{array}{l}38 \% \text { Glass cloth } \\
62 \% \text { Teflon }\end{array}$ & 0.0135 & 0.004 \\
\hline
\end{tabular}

(1) Radial direction is perpendicular to molding pressure and through glass cloth layers.

(2) Width direction is parallel to molding pressures and glass cloth layers.

(3) From manufacturer's data 
TABLE III - TEST-BEARING RETAINERS ( ref, 6)

(Deep-groove ball bearings, 40-mm bore, separable at outer race; races and balls, AISI 440C stainless steel; number of balls, 10; ball diameter, $0.37 .5 \mathrm{in} .(0.953 \mathrm{~cm})$; inner- and outer-race curvature, 0.54 ; radial clearance, 0.0025 in. $(0.0064 \mathrm{~cm})$.)

\begin{tabular}{|c|c|c|c|c|c|c|c|}
\hline \multirow[t]{2}{*}{ Retainer } & \multirow{2}{*}{$\begin{array}{l}\text { Approximate weight } \\
\text { percent of materials }\end{array}$} & \multirow{2}{*}{$\begin{array}{l}\text { Retainer } \\
\text { construction }\end{array}$} & \multirow[t]{2}{*}{ Bearing } & \multicolumn{2}{|c|}{ Inner land clearance } & \multicolumn{2}{|c|}{ Ball pocket clearance } \\
\hline & & & & in. & $\mathrm{cm}$ & in. & $\mathrm{cm}$ \\
\hline \multirow[t]{2}{*}{1} & \multirow{2}{*}{$\begin{array}{l}38 \text { Percent glass cloth } \\
\text { leminates with } 62 \text { per- } \\
\text { cent PTFE binder }\end{array}$} & \multirow{2}{*}{$\begin{array}{l}\text { One-piece body } \\
\text { with riveted } \\
\text { aluminum side } \\
\text { plates }\end{array}$} & $13-S$ & 0.0 .18 & 0.046 & 0.019 & 0.048 \\
\hline & & & $16-\mathrm{s}$ & 0.017 & 0.043 & 0.015 & 0.038 \\
\hline \multirow[t]{2}{*}{2} & \multirow{2}{*}{$\begin{array}{l}15 \text { Percent glass fibers } \\
5 \text { percent molybdenum } \\
\text { disulfide, } 80 \text { percent } \\
\text { PTFE }\end{array}$} & \multirow{2}{*}{$\begin{array}{l}\text { One-piece body } \\
\text { rith no external } \\
\text { support }\end{array}$} & \multirow{2}{*}{$\begin{array}{l}14-S \\
23-S\end{array}$} & $0.0 \% 1$ & 0.079 & 0.014 & 0.036 \\
\hline & & & & $b_{0.048}$ & $b_{0.122}$ & 0.018 & 0.046 \\
\hline \multirow[t]{2}{*}{3} & \multirow{2}{*}{$\begin{array}{l}15 \text { to } 20 \text { Percent glass } \\
\text { fibers, balance } \\
\text { PrFE, c }\end{array}$} & \multirow{2}{*}{$\begin{array}{l}\text { One-piece body } \\
\text { with one-piece } \\
\text { riveted aluminum } \\
\text { shroud. }\end{array}$} & \multirow{2}{*}{$\begin{array}{l}15-S \\
22-S\end{array}$} & 0.035 & 0.089 & 0.016 & 0.041 \\
\hline & & & & 0.035 & 0.089 & 0.026 & 0.066 \\
\hline \multirow[t]{2}{*}{4} & \multirow{2}{*}{$\begin{array}{l}30 \text { Percent bronze } \\
\text { powder, } 70 \text { percent } \\
\text { PTFE }\end{array}$} & \multirow{2}{*}{$\begin{array}{l}\text { One-piece body } \\
\text { W th no external } \\
\text { sipport }\end{array}$} & $20-5$ & 0.038 & 0.097 & 0.018 & 0.046 \\
\hline & & & $21-S$ & $\begin{array}{l}0.019 \text { to } \\
0.066\end{array}$ & $\begin{array}{l}0.048 \text { to } \\
3.08\end{array}$ & 0.016 & 0.041 \\
\hline 5 & $\begin{array}{l}78 \text { Percent copper, } \\
9 \text { percent PIFE, } \\
13 \text { percent } e^{\text {tungsten }} \\
\text { diselenide }\end{array}$ & $\begin{array}{l}\text { Shrink-fit one- } \\
\text { piece stainless- } \\
\text { steel shroud over } \\
\text { one-piece body } \\
\text { pinned in two } \\
\text { places } 180^{\circ} \text { apart }\end{array}$ & $17-\mathrm{s}$ & 0.027 & 0.069 & 0.015 & 0.038 \\
\hline \multirow[t]{2}{*}{6} & \multirow{2}{*}{$\begin{array}{l}85 \text { Percent silver, } \\
5 \text { percent PTFE, } \\
10 \text { percent tungsten } \\
\text { diselenide }\end{array}$} & $\begin{array}{l}\text { Same as retainer } \\
5 \text { material with- } \\
\text { out } 2 \text { pins }\end{array}$ & $11-S$ & 0.024 & 0.061 & 0.015 & 0.038 \\
\hline & & $\begin{array}{l}\text { Same as retainer } \\
5 \text { materiol }\end{array}$ & $18-5$ & 0.025 & 0.064 & 0.015 & 0.038 \\
\hline \multirow[t]{2}{*}{7} & \multirow[t]{2}{*}{$\begin{array}{l}85 \text { Percent polyimide, } \\
15 \text { percent molybdenum } \\
\text { disulfide }\end{array}$} & $\begin{array}{l}\text { Shrink-fit one- } \\
\text { piece aluminum } \\
\text { shroud over one- } \\
\text { piece body }\end{array}$ & $12-S$ & 0.022 & 0.056 & 0.016 & 0.041 \\
\hline & & $\begin{array}{l}\text { Shrink-fit one- } \\
\text { piece aluminum } \\
\text { shroud over one- } \\
\text { piece body with } \\
2 \text { pins } 180^{\circ} \\
\text { apart }\end{array}$ & $19-5$ & 0.019 & 0.048 & 0.016 & 0.041 \\
\hline
\end{tabular}

Manufacturer's data.

' Machined to' this clearance after running one test with $0.023-i n .(0.058 \mathrm{~cm})$ clearance .

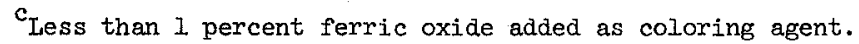

Inner diameter of retainer machined eccentric.

Metal composites weight percent calculated from measured specific gravity values. 
TABLE IV. - COMPARISON OF BALL SPIN TORQUES OF TWO $40 \mathrm{~mm}$ BATL BEARINGS. TORQUE ABOUT BEARING AXIS - LB-IN.

$$
\begin{aligned}
& T=1001 \mathrm{~b}, \quad \mathrm{~N}=40000 \mathrm{rpm}, \\
& \beta^{*}=10^{\circ}, \quad f=0.56
\end{aligned}
$$

\begin{tabular}{|c|c|c|}
\hline Race Curvatures & $\rho_{1}=0.51, \rho_{0}=0.58$ & $\rho_{1}=0.52, \rho_{0}=0.54$ \\
\hline $\begin{array}{c}108 \text { Series } \\
d=0.375 \text { in. }\end{array}$ & 2.095 & 1.653 \\
\hline $\begin{array}{c}1908 \text { Series } \\
d=0.250 \text { in. }\end{array}$ & 1.831 & 1.412 \\
\hline
\end{tabular}

TABIE V. - THRUST BEARING DESIGN CONFIGURATIONS FOR IIQUID HYDROGEN

\begin{tabular}{|c|c|c|c|c|c|c|}
\hline $\begin{array}{c}\text { Shaft } \\
\text { diameter, } \\
\text { mm } \\
\text { (bearing } \\
\text { bore) }\end{array}$ & $\begin{array}{c}\text { Shaft } \\
\text { rpm }\end{array}$ & $\begin{array}{c}\text { Thrust } \\
\text { load, } \\
\text { Ib }\end{array}$ & $\begin{array}{c}\text { DN Value } \\
\text { (bearing bore, } \\
\text { mm } \times \text { shaft } \\
\text { speed, rom) }\end{array}$ & $\begin{array}{c}\text { Ball } \\
\text { diam- } \\
\text { eter, } \\
\text { in. }\end{array}$ & $\begin{array}{c}\text { Number } \\
\text { of } \\
\text { balls }\end{array}$ & $\begin{array}{c}\text { Ball } \\
\text { centrif- } \\
\text { ugal } \\
\text { force, } \\
\text { 1b }\end{array}$ \\
\hline 40 & 50000 & 100 & $2.00 \times 10^{6}$ & 0.250 & 14 & 32 \\
50 & 24000 & 2000 & $1.20 \times 10^{6}$ & 0.438 & 16 & 56 \\
110 & 16400 & 15000 & $1.80 \times 10^{6}$ & 0.719 & 20 & 227 \\
250 & 16000 & $-\ldots-00 \times 10^{6}$ & 2.375 & 17 & 17300 \\
150 & 26000 & 1000 & $3.90 \times 10^{6}$ & 0.625 & 19 & 584 \\
200 & 15000 & 5000 & $3.00 \times 10^{6}$ & 0.875 & 24 & 608 \\
\hline
\end{tabular}




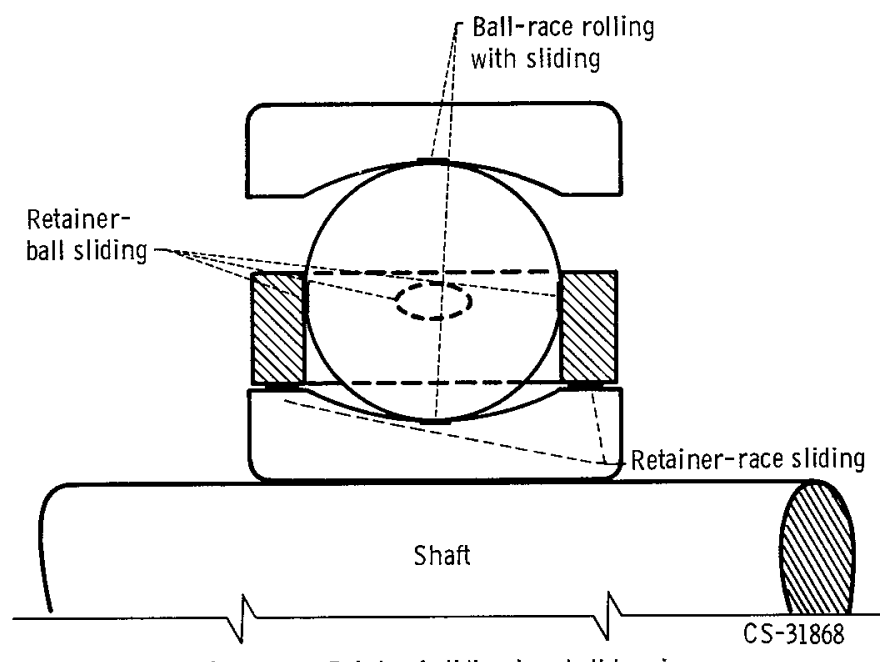

Figure 1. - Points of sliding in a ball bearing.

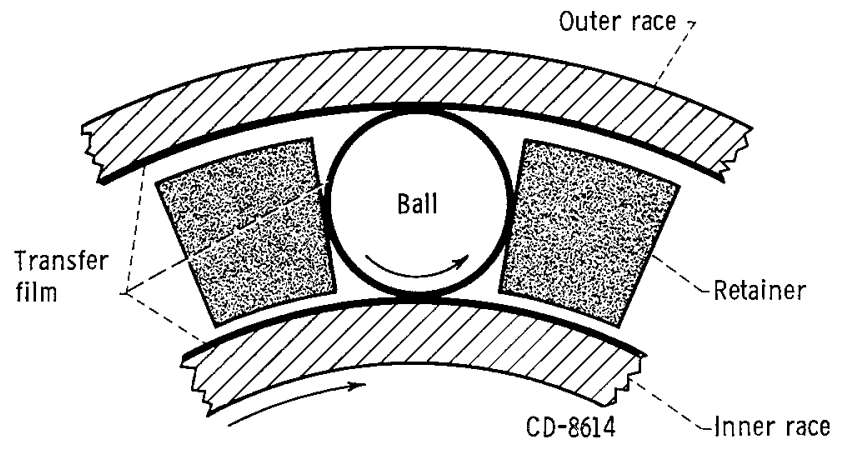

Figure 2. - Film transfer mechanism.

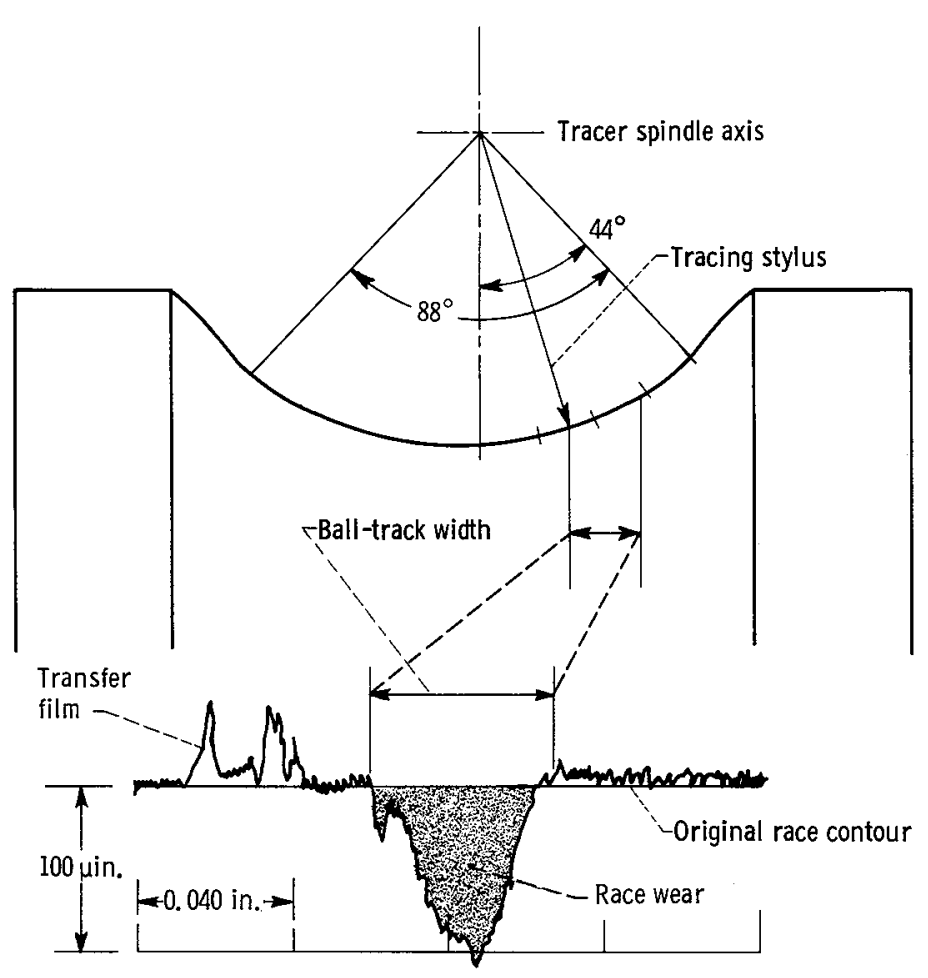

Figure 3. - Profile trace of bearing inner race normal to ball-rolling direction. 


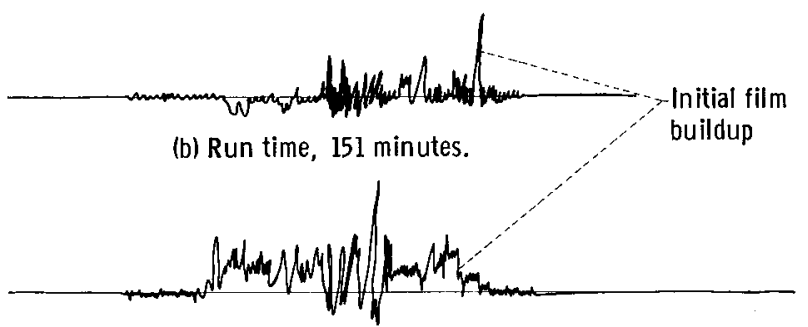

(c) Run time, 284 minutes.

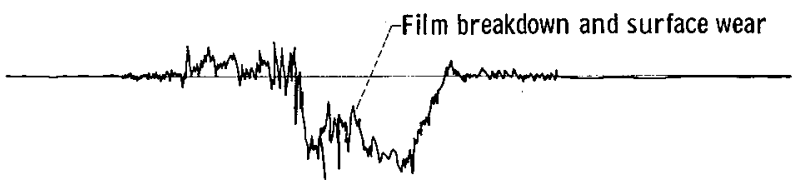

(d) Run time, 404 minutes.

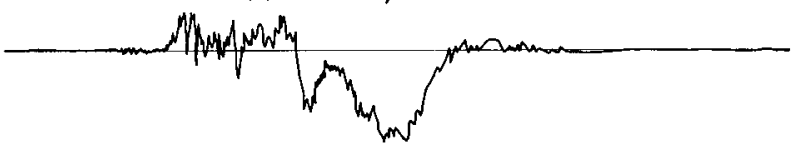

(e) Run time, 520 minutes.

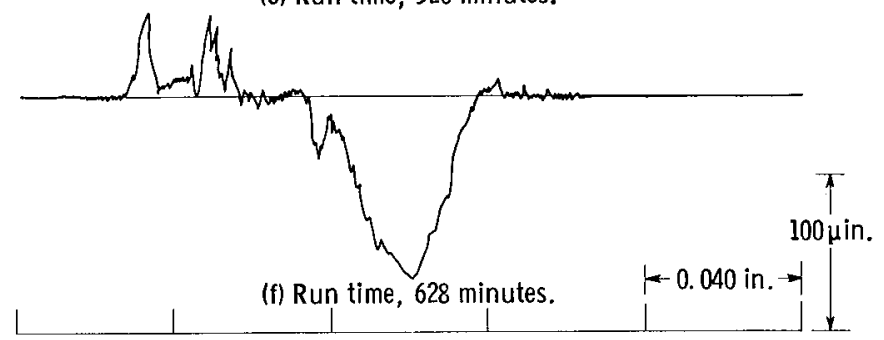

Figure 4. - Progressive profile traces of inner-race groove (normal to ballrolling direction). Retainer material, 38 percent glass cloth with 62 percent PTFE binder; shaft speed, $20000 \mathrm{rpm}$; thrust load, 200 pounds: coolant, hydrogen gas at $60^{\circ}$ R. (Ref. 6.)

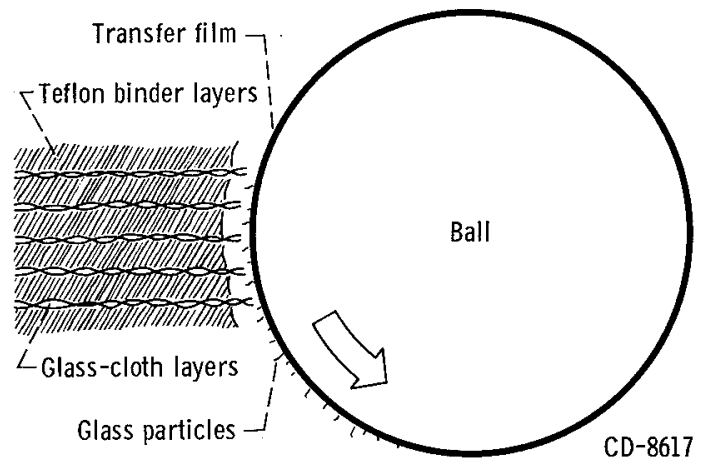

Figure 5. - Postulated wear process in ball pocket of glasscloth-with-PTFE-binder retainer. (Ref. 6.) 


\section{$\mathrm{E}-3453$}

(a) Run time, 0 minutes.

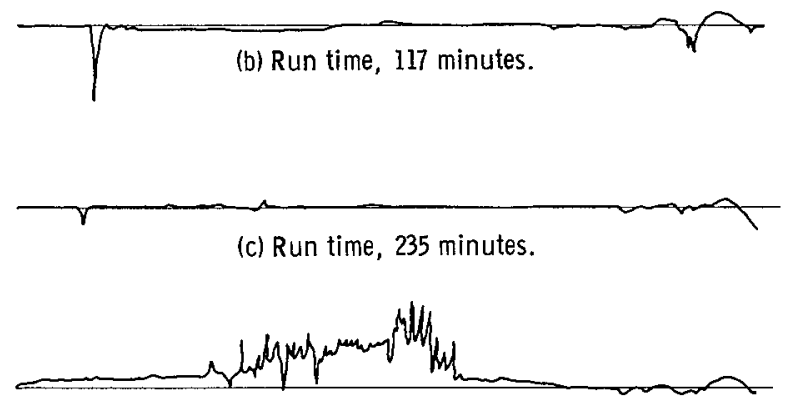

(d) Run time, 350 minutes.
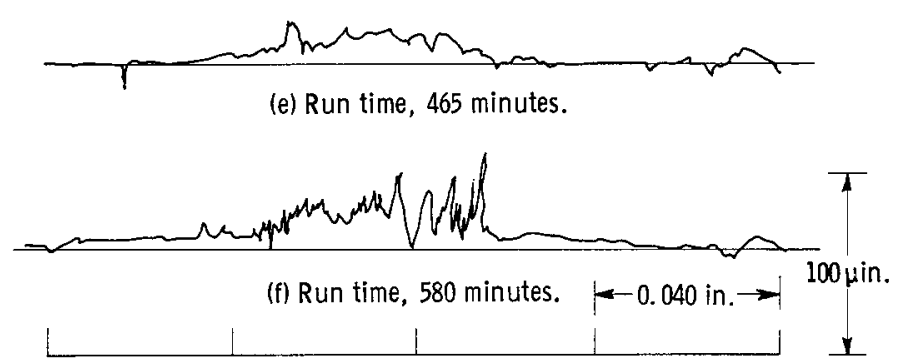

Figure 6. - Progressive profile traces of inner-race groove (normal to ballrolling direction). Retainer material, 15 percent glass fibers and 85 percent PTFE; shaft speed, 20000 rpm; thrust load, 200 pounds: coolant, hydrogen gas at $60^{\circ} \mathrm{R}$. (Ref. 6.) (a) Run time, 0 minutes.

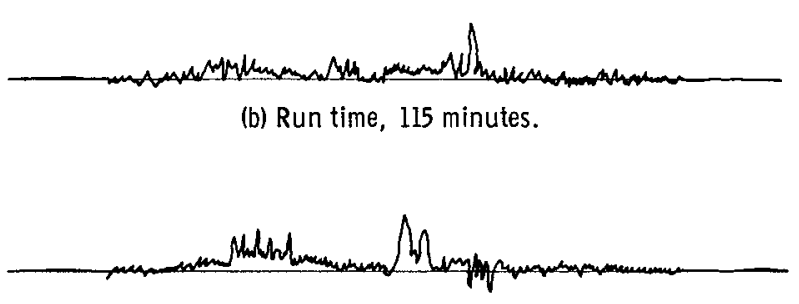

(c) Run time, 229 minutes.

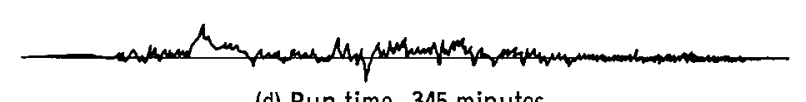

(d) Run time, 345 minutes.

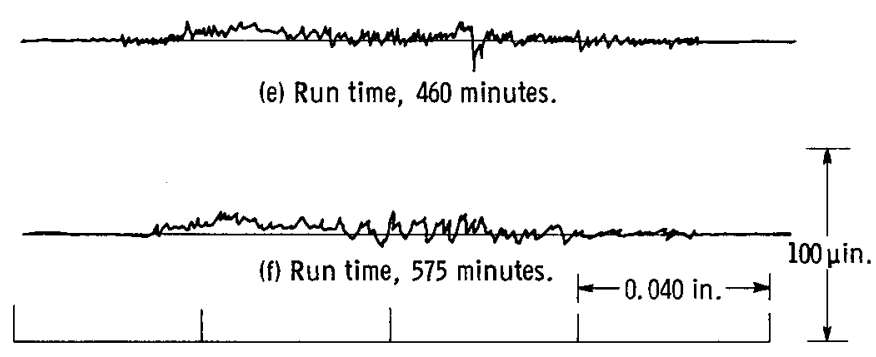

Figure 7. - Progressive profile traces of inner-race groove (normal to ballrolling direction). Retainer material, 30 percent bronze powder and 70 percent PTFE; shaft speed, $20000 \mathrm{rpm}$; thrust load, 200 pounds: coolant, hydrogen gas at $60^{\circ} \mathrm{R}$. (Ref. 6.) 


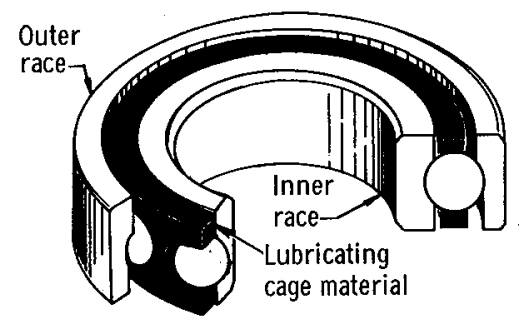

(a) One-piece body with no external support.

in

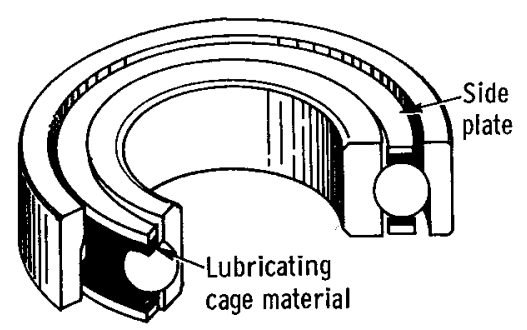

(b) One-piece body with side plates.

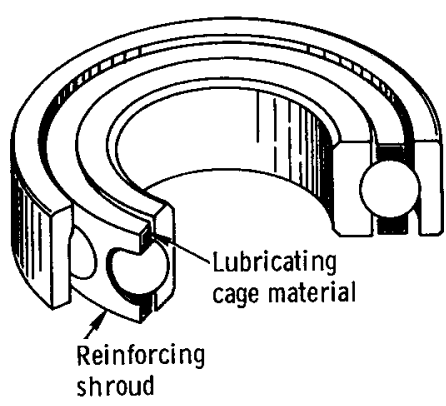

(c) One-piece body with one-piece shroud.

Figure 8. - Inner-race located cage designs.

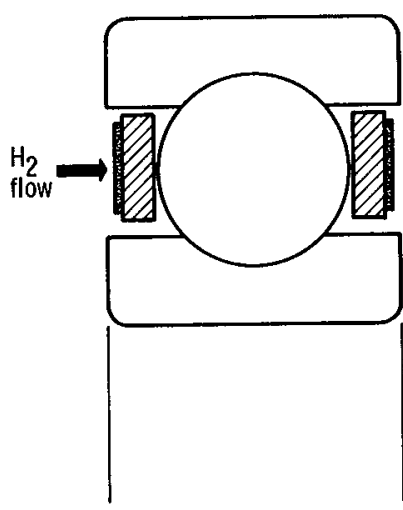

(a) Conventional design.

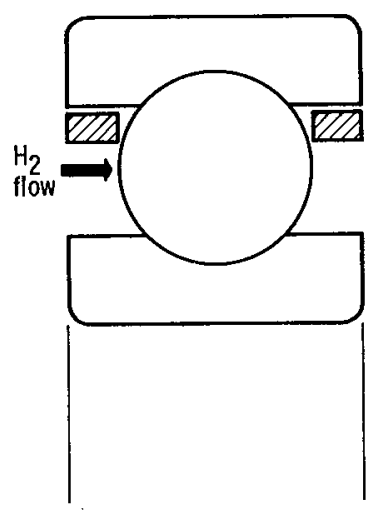

(b) Thin-line design.

Figure 9. - Outer-race located cage designs. 


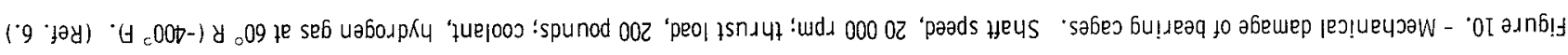

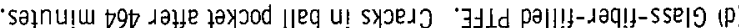

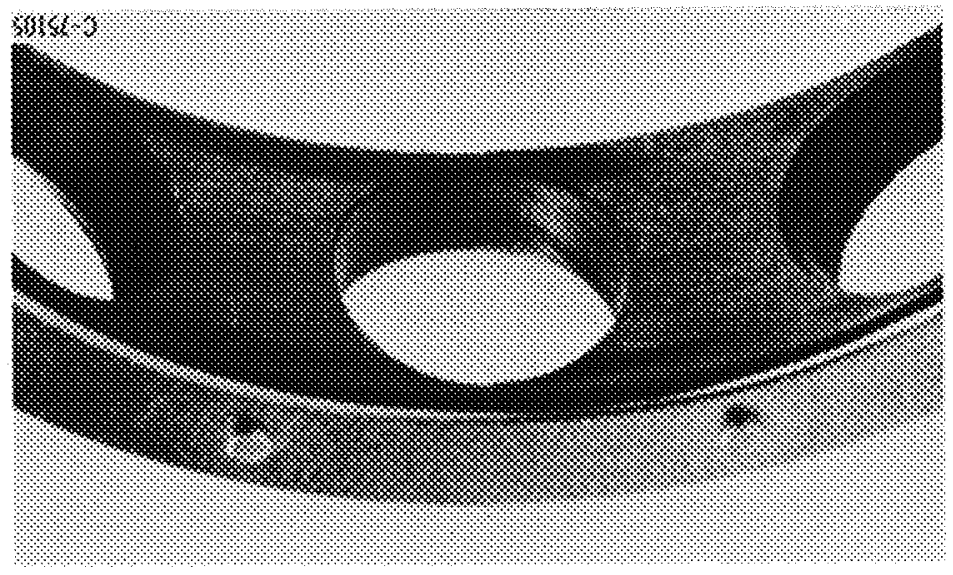

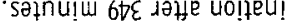

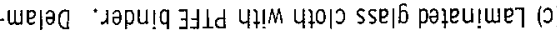

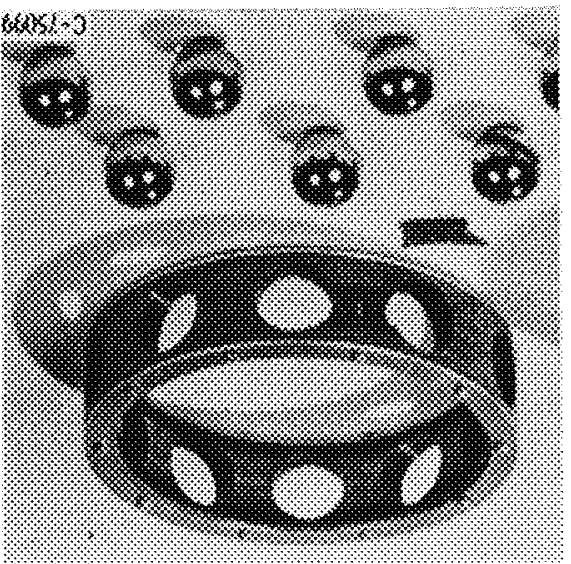

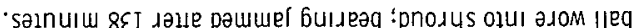

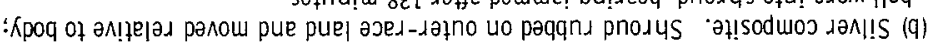

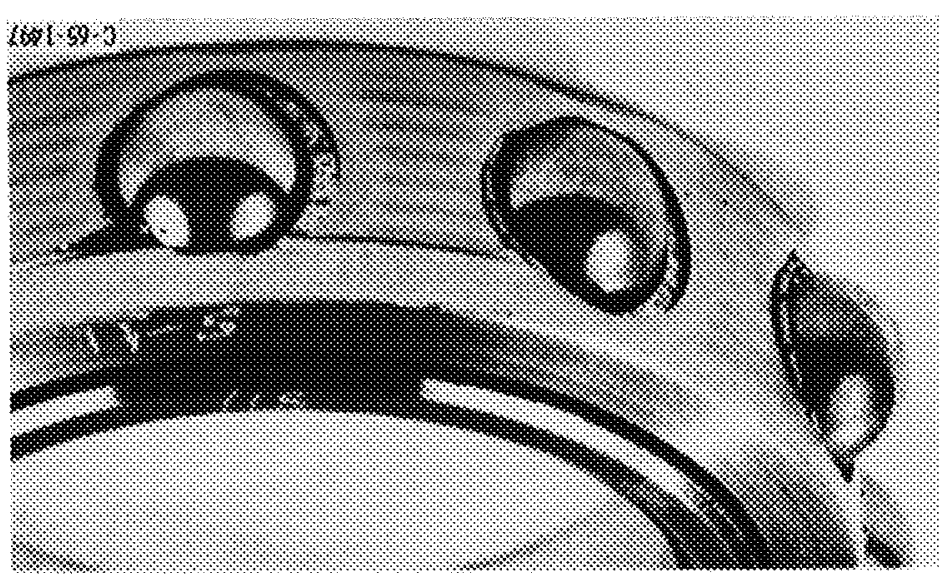

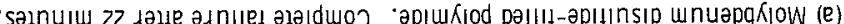

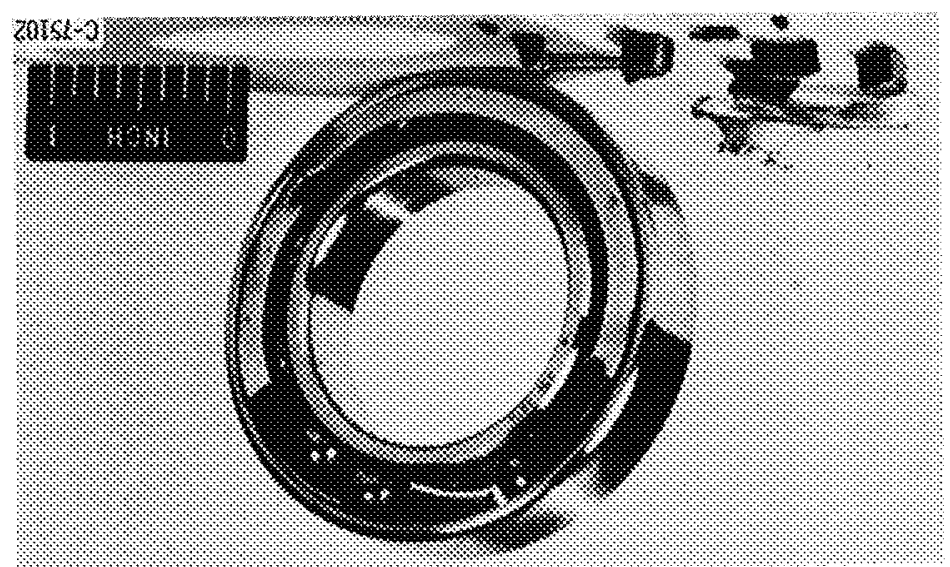



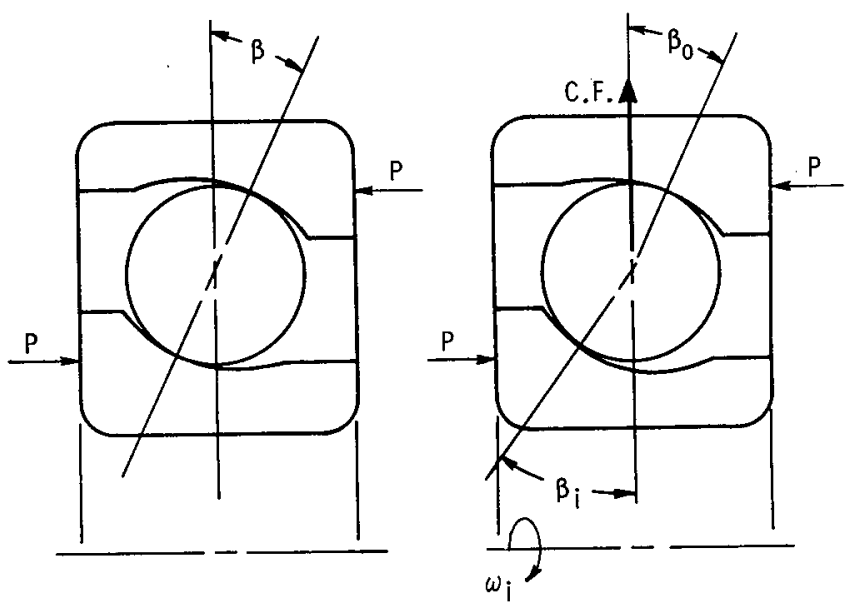

(a) Contact angle when under load. (b) Contact angles when under load and at high speed.

Figure 11. - Effect of high shaft speed on bearing contact angle.

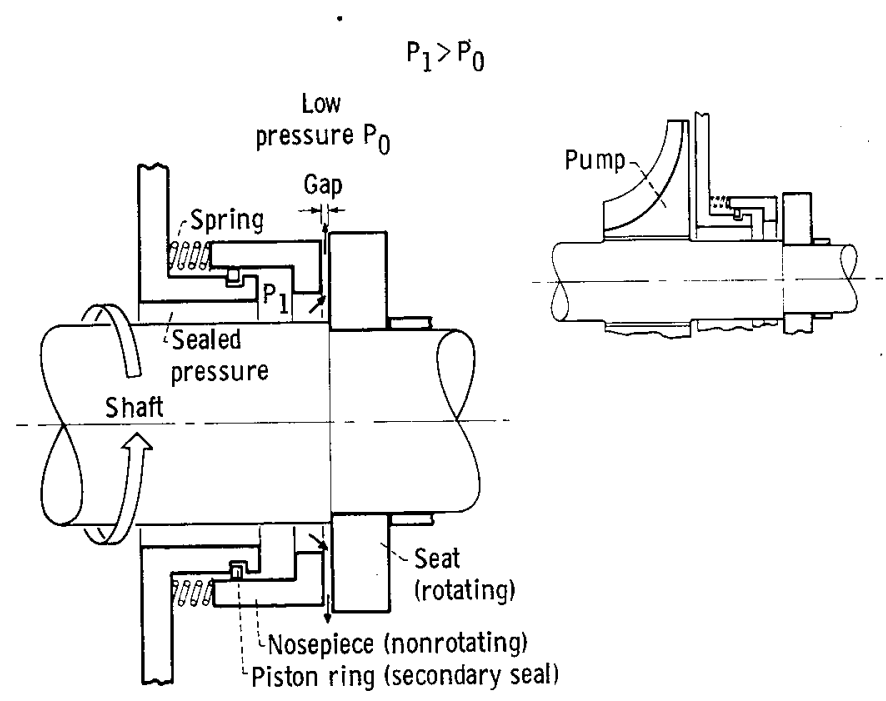

Figure 13. - Face contact seal (ref. 2).

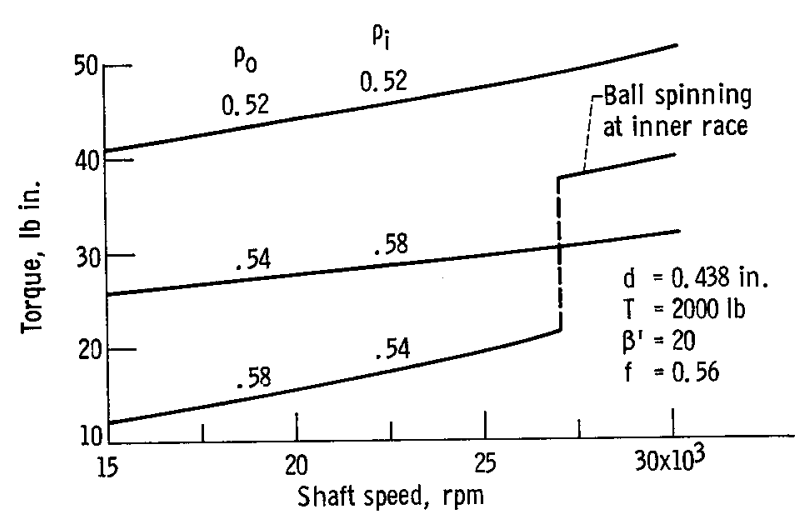

Fiqure 12. - Torque due to ball spinning for 50 millimeter (210 series) bearings.

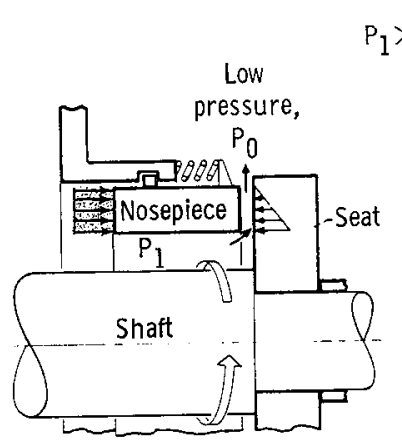

(a) Pressure loaded.

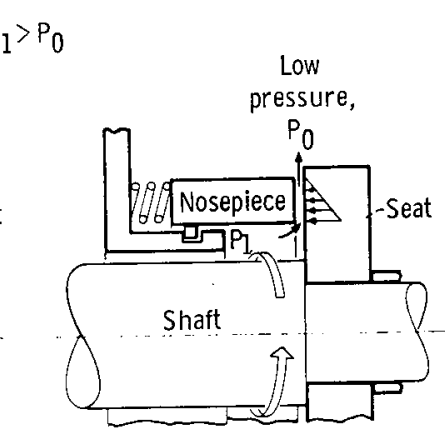

(b) Pressure unloaded.
Figure 14. - Unbalanced face contact seals (ref. 2). 

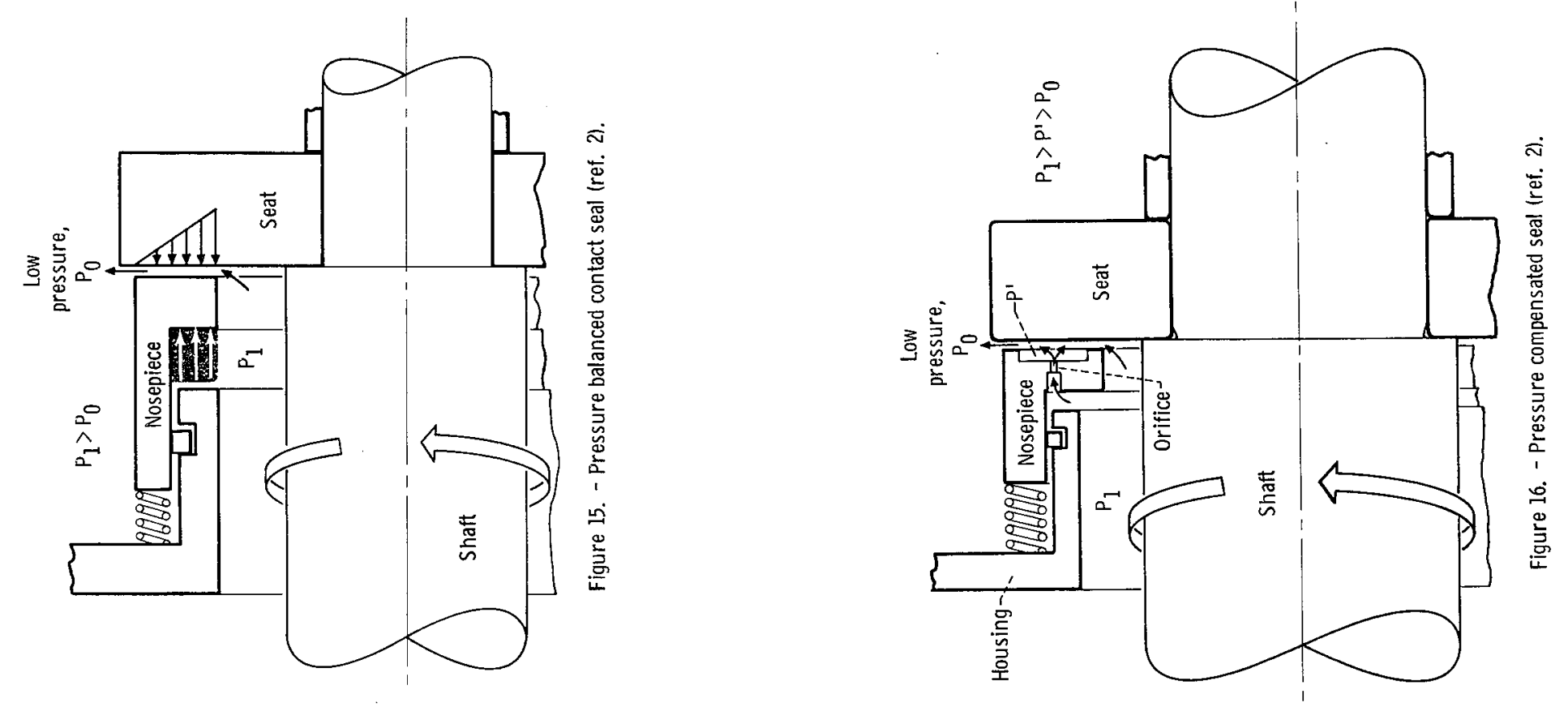

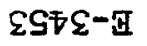



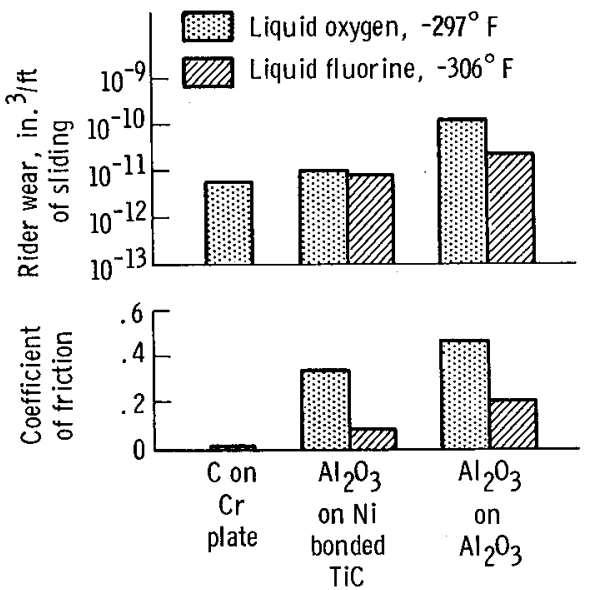

Figure 17. - Friction and wear of potential seal material combinations in liquid oxygen and liquid fluorine. Sliding velocity, 2300 feet per minute; load, 1000 grams. (Ref. 8.)
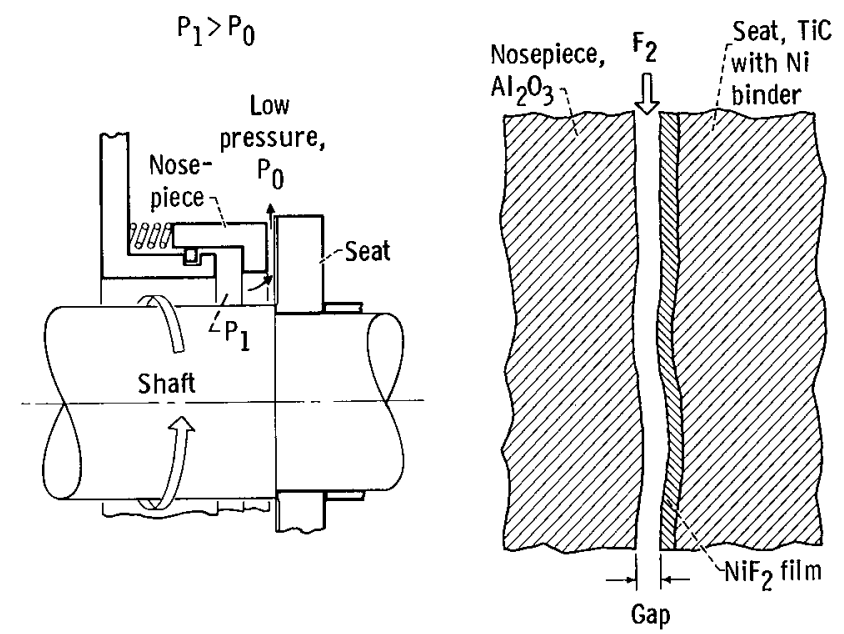

(a) Pressure balanced design.

(b) Schematic of lubricating mechanism.

Figure 18. - Liquid fluorine seal (ref. 2). 